\title{
Developing Competence, Conscience, and Compassion through Reflective Pedagogy
}

\author{
Fransisca Kristanti \\ English Letters Department \\ Sanata Dharma University \\ Yogyakarta, Indonesia \\ f.kristanti@usd.ac.id
}

\begin{abstract}
This paper outlines how Reflective Pedagogy contributes to the development of students' holistic learning by developing their competence, conscience, and compassion in Speaking class. The application of Reflective Pedagogy, which sets out a learning cycle from context understanding to evaluation, and the employment of student-focused topics allow a more holistic learning process to take place. Giving students more opportunity to experience a full cycle of learning from planning to performance results in a deeper level of learning. Furthermore, trusting students with the responsibility in the conduct of their learning course, provided with appropriate approach and structured monitoring, leads to a more thorough development. Utilizing self-evaluation and peer-evaluation rubrics is a way to sharpen the students' cognitive awareness, whereas self-reflection and peer-feedback forms enable them to develop their conscience by exercising their empathy towards themselves and others as well as to reinforce their compassion by accepting and giving assistance to their peers. Furthermore, a recorded speech performance enables students to reflect and evaluate themselves and become essential to raise the students' awareness of their strengths and needs. This collaboration allows them to develop their competence, conscience, and compassion in their own pace.
\end{abstract}

Keywords: Reflective pedagogy, competence, conscience, compassion

\section{INTRODUCTION}

Accomplishment beyond cognitive achievement is central in higher education. Reflective pedagogy emphasizes not only on how well we develop our knowledge, but also on our choice of action in learning, our consideration of the reason behind the choices, and our rumination about whether it works. Reflective pedagogy requires us to go through a process of self-observation and evaluation. When we are able to shift our focus from the classroom materials to our own learning process, we are able to gather information about our own learning. Furthermore, this information serves as the basis of further analysis and evaluation which enables us to identify our best practices and beliefs. As [1] stated:

What [an individual] has learned in the way of knowledge and skill in one situation becomes an instrument of understanding and dealing effectively with the situation which follow. The process goes on as long as life and learning continue (44).

Reference [2] claims that experience requires continuous interaction in order to make it dynamic, and reflective pedagogy allows us to create meanings from our learning experience which later enables us to comprehend and put value to those processes which involves recognition, examination, and judgment over our choices of actions. This may then result in changes and improvements of our learning performance.

Reflection holds a key role in thorough development of learning practices. As individuals carry their own context, experience, belief, expectation, and attitudes towards learning, the reflection process might lead to different comprehension and value of the learning process. This becomes a valuable opportunity for them to develop not only ourselves, but also others in our learning environment. The different understanding of learning may result in different ability to value learning, and these differences are the key to develop oneself beyond one's cognition.

Sanata Dharma University is committed to the whole person education by imposing Ignatian Pedagogy, which is a form of reflective pedagogy, in its curriculum. As the only Jesuit University in Indonesia, Sanata Dharma University maintain the goal of Jesuit education which is forming men and women for others, as written in [3]: "men and women of competence, conscience and compassionate commitment," (5). Therefore, reflective pedagogy becomes the foundation of the learning activity.

Reflective pedagogy explores the possibility of the implication of the learning process with the intention of understanding and improving the learning process. Reference [4] suggests that the practice of reflective teaching is a continuous process that thoughtfully involves learners and that is taken one's own experience as a learning factors in the application of knowledge during the course of learning. This experience helps the person to develop analysis of feelings and evaluation of experience, among others.

The method of reflective learning has been applied in education for decades. It aims the context of life-long and experiential learning. Reference [5] state that many educators have identified reflective practice as an essential 
factor in the substance of experiential setting. Reference [6] specifically defines reflection as "the process of stepping back from an experience to ponder, carefully and persistently, its meaning to the self through the development of inferences" (39).

Furthermore, reflective learning does not only facilitate cognitive development, but also affective and moral development as stated in [7] and [8]. Therefore, the practice of reflective pedagogy is used in the process of experiential learning to develop not only competence, but also conscience and compassion.

\section{METHOD}

The research employed a model which was developed based on the principles of reflective skills development: 1) a dialog in a form of consultation which encourage students to make choices based on their ideas and beliefs in specific situations and 2) the fact that certain situation may involves unpredicted result, failure, and frustration as stated in [9]. To provide feedback on what to reflect, every performance was recorded and every student got the video of the performance. Students were also provided with learning journals, performance rubrics and peer-feedback forms.

Participants were 30 students of Speaking IV class which consisted of 5 males and 25 females with the average age of 20,3 years. The decision to take Speaking IV class was partially due to the characteristic of the course which allows various contexts to be expressed by the students. The research was initiated in the beginning of spring semester 2017 and is still in progress. Therefore, this article will present the findings from the data taken in the first half of the semester, covering 2 speech performances.

At the start of the semester, the participants were introduced to the course design which presented the objectives of the course, the tools of reflective practice, course requirements and deadlines, and consultation schedule. During the course of the semester, each participant submitted a written reflection after every performance. The reflection was made based on the feedbacks they got during the process including their performance videos, learning journals, performance rubrics and peer feedbacks.

Students' reflection was designed to express the participants' experience from two perspectives, their strengths and weaknesses. The design involved the themes presented in [4]: 1) what was unexpected, 2) what was unsuccessful and 3) what was frustrating, and the counterthemes: 1) what was expected, 2) what was successful and 3) what was pleasing. Students' reflection covers the information about the contributing factors of students' development. A total of 60 written reflections were collected, 2 from each student. The developmental objectives of the competence are the content and the delivery of the speech. There were two developmental objectives in the area of conscience: 1) independence and proactivity in the speech development process and 2) openness to differences. Finally, the developmental objectives of students' compassion in this class are 1) active contribution in developing peer performance and 2) application of context in their speeches as tools to bring social and natural issues into light.

Finally, a survey was given to assess the efficacy of the practice of reflective pedagogy. Participant completed a survey conducted after the submission of the second reflection.

\section{FINDING AND DISCUSSION}

Participants completed a survey consisting 14 items using a 4-point Likert-type scale with 1 as strongly disagree and 4 strongly agree as endpoints. The questions were designed around 4 themes which are related to the holistic coverage, they are 1) overall evaluation, 2) competence diagnostic value, 3) conscience diagnostic value and 4) compassion diagnostic value. The result of the survey is reported in Table 1.

Table 1. Participant's Evaluation of Reflective Pedagogy

\begin{tabular}{|c|c|c|}
\hline Theme & Mean & $\begin{array}{l}\text { Standard } \\
\text { Deviation }\end{array}$ \\
\hline \multicolumn{3}{|l|}{ Overall evaluation } \\
\hline $\begin{array}{l}\text { I have benefited from the process of } \\
\text { writing reflection }\end{array}$ & 3.50 & 0.51 \\
\hline $\begin{array}{l}\text { The performance videos were useful for } \\
\text { my development }\end{array}$ & 3.63 & 0.49 \\
\hline $\begin{array}{l}\text { The learning journal was useful for my } \\
\text { development }\end{array}$ & 3.17 & 0.65 \\
\hline $\begin{array}{l}\text { The performance rubrics were useful for } \\
\text { my development }\end{array}$ & 3.63 & 0.49 \\
\hline $\begin{array}{l}\text { The peer-feedback were useful for my } \\
\text { development }\end{array}$ & 3.53 & 0.51 \\
\hline \multicolumn{3}{|l|}{ Competence diagnostic value } \\
\hline $\begin{array}{l}\text { The process helped me to identify my } \\
\text { strength in giving speeches }\end{array}$ & 3.10 & 0.80 \\
\hline $\begin{array}{l}\text { The process helped me to identify my } \\
\text { weaknesses in giving speeches }\end{array}$ & 3.70 & 0.47 \\
\hline $\begin{array}{l}\text { The process helped me to understand } \\
\text { what I wanted to gain in this class } \\
\text { and how to gain it }\end{array}$ & 3.33 & 0.48 \\
\hline \multicolumn{3}{|l|}{ Conscience diagnostic value } \\
\hline $\begin{array}{l}\text { The process helped me to become more } \\
\text { responsible in finding resources to } \\
\text { develop my speeches }\end{array}$ & 3.20 & 0.61 \\
\hline $\begin{array}{l}\text { The process helped me to become more } \\
\text { proactive in developing speeches }\end{array}$ & 3.53 & 0.51 \\
\hline $\begin{array}{l}\text { The process helped me to understand my } \\
\text { context and others' contexts }\end{array}$ & 3.80 & 0.41 \\
\hline Compassion diagnostic value & & \\
\hline $\begin{array}{l}\text { The process increased my participation in } \\
\text { developing my friends' performance }\end{array}$ & 3.30 & 0.75 \\
\hline $\begin{array}{l}\text { The process helped me become aware to } \\
\text { the social issues around me }\end{array}$ & 3.47 & 0.51 \\
\hline $\begin{array}{l}\text { The process helped me make contextual } \\
\text { contribution to the society }\end{array}$ & 3.07 & 0.64 \\
\hline
\end{tabular}

Table 1 indicates that the participants found the reflective pedagogy model to be beneficial for their development. The reflective tools used in the learning process were found useful for their development in 
Speaking IV class. The reflective process contributes to the development of competence mainly for the identification of the aspects that need to be developed by students in performing speeches. In the conscience aspect, the process mainly contributes to their understanding of context, both theirs and others, whereas in the compassion aspect, it contributes the most to their awareness of the social issues around them.

The development of competence, conscience and compassion through the application of reflective pedagogy is the main purpose of this study. Even though the result of the survey shows the effectiveness of the method in developing students' competence, conscience and compassion, it needs more detailed supports based on the developmental objectives that are elaborated in students' reflections. It can be seen in the table 2 .

Table 2. Summary of Participant's Reflection on

\section{Competence}

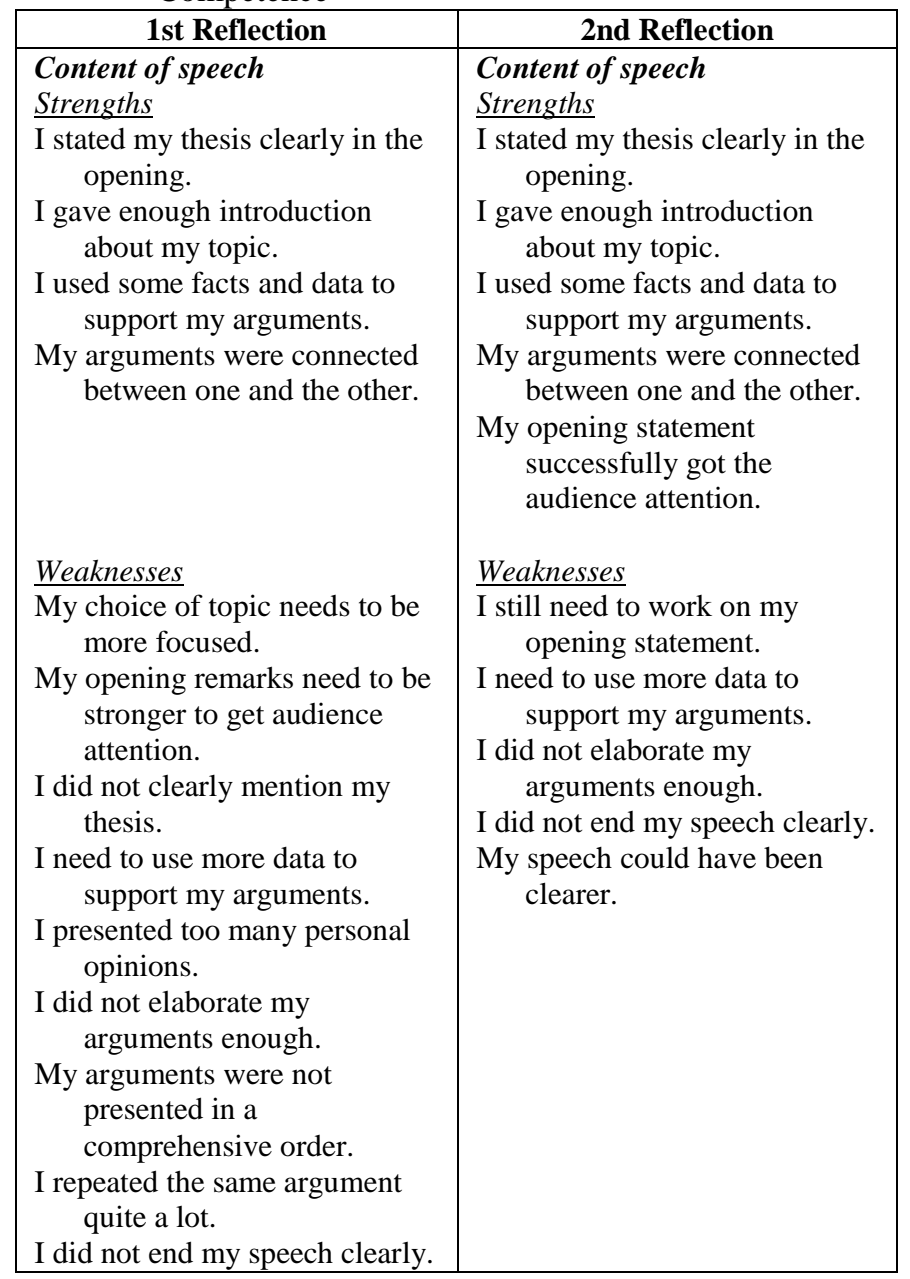

Table 2. Cont

\begin{tabular}{|c|c|}
\hline $\begin{array}{l}\text { Delivery of speech } \\
\text { Strengths } \\
\text { I used understandable } \\
\text { vocabulary. } \\
\text { My pronunciation and } \\
\text { intonation were okay. } \\
\text { I made eye-contact with the } \\
\text { audience } \\
\text { Weaknesses } \\
\text { I said to many filler phrases } \\
\quad \text { (e.g. you know guys, what } \\
\text { is it? okay). } \\
\text { I should have spoken louder. } \\
\text { I still made grammatical errors. } \\
\text { I mispronounced some words. } \\
\text { My hands moved a lot. } \\
\text { I need to make more eye- } \\
\text { contact. } \\
\text { My expression looked very } \\
\text { nervous. } \\
\text { I should move around more. } \\
\text { I should not move too much. }\end{array}$ & $\begin{array}{l}\text { Delivery of speech } \\
\text { Strengths } \\
\text { My speech was understandable. } \\
\text { I used contextual vocabulary. } \\
\text { I made eye-contact with the } \\
\text { audience. } \\
\text { My voice was loud and clear. } \\
\text { Weaknesses } \\
\text { I said to many filler phrases } \\
\quad \text { (e.g. you know guys, what } \\
\text { is it? okay). } \\
\text { I still made simple grammatical } \\
\text { errors. } \\
\text { My hands moved a lot. } \\
\text { My expression looked very } \\
\text { nervous. } \\
\text { I should move around more. }\end{array}$ \\
\hline
\end{tabular}

Table 2 presents the summary of participants' evaluation regarding their competence. From the information, it can be seen that the participants identify more items on their weaknesses than their strengths as shown in the survey as well. However, the 2 nd reflection shows an increase in participants' identification of strengths and a decrease of their weaknesses compared to the 1st reflection. Contradicting evaluations such as the quality of the opening remarks, the clarity of the thesis statement, the elaboration of arguments, and the making of eye-contact also found more in the 1 st reflection than in the 2 nd reflection. This indicates that during the process of learning between the $1 \mathrm{st}$ and the 2nd performance, the participants experience changes which reduced the variety of their weaknesses and increase the variety of their strength based on their reflection of their competence. This is also shown in their progress score average as shown in Table 3.

Table 3. Participant's Average Achievement

\begin{tabular}{|l|c|c|}
\hline \multirow{2}{*}{ Items of scoring } & \multicolumn{2}{|c|}{ Average Score } \\
\cline { 2 - 3 } & Test 1 & Test 2 \\
\hline Content & & \\
Contextuality of topic & 68.33 & 92.24 \\
Thesis statement & 65.00 & 81.89 \\
Supporting material & 71.67 & 81.03 \\
Organization & 68.33 & 84.48 \\
Delivery & & \\
Language selection & 78.33 & 73.27 \\
Clarity of voice & 76.67 & 96.55 \\
Accuracy & 76.67 & 75.86 \\
Physical behaviors & 60.00 & 82.75 \\
\hline
\end{tabular}

An increase of achievement occurs in almost all aspects of competence scoring. The highest increase occurs in the aspect of topic contextuality. This shows the development in the participants' understanding of their context which allows 
them to select more contextual topics in their speech. The aspects of language selection and accuracy, however, experience a decrease of achievement. This is related to their vocabulary and structure mastery which needs to be paid attention more. It can be seen in the table 4

Table 4. Summary of Participant's Reflection on Conscience

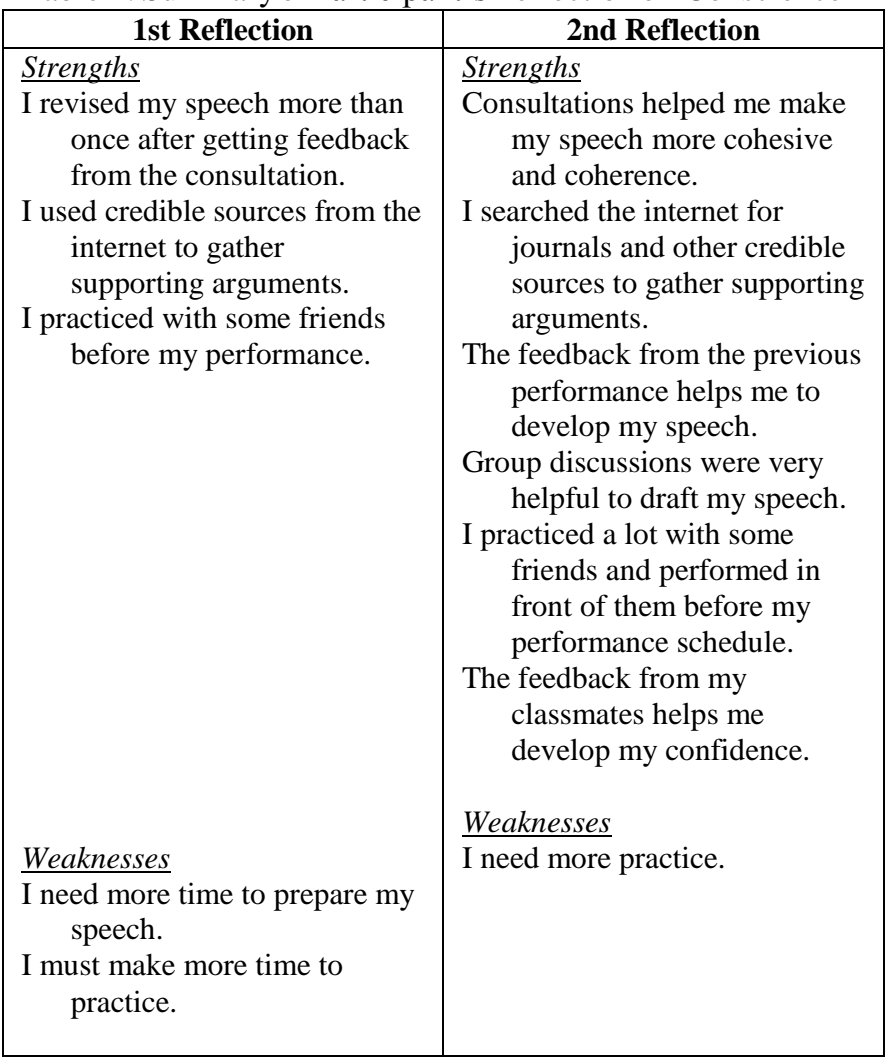

Table 4 presents the summary of the participants' reflection in the conscience aspect. In contrast to the result of the reflection in the aspect of competence, the reflection in the aspect of conscience shows more strengths than weaknesses. The number of strengths identification increases in the 2nd reflection. This illustrates the participants' development in this particular aspect. Changes that are visible are in their preparation effort. The participants state group discussions and practices help them in their speech writing and performance. Nevertheless, the reflections do not reveal anything about contextual understanding of others, as intended as one of the focuses in this aspect. It is, however, mentioned that the feedback from the classmates helps them develop their confidence. Even though this study does not present the analysis of the peer feedback, the peer feedback mostly started with an acknowledgement of the performer's strengths and continued with suggestions of improvements. This shows the existence of contextual understanding of others.
Table 5. Summary of Participant's Reflection on Compassion

\begin{tabular}{|c|c|}
\hline 1st Reflection & 2nd Reflection \\
\hline $\begin{array}{c}\text { Strengths } \\
\text { Feedbacks from my friends } \\
\text { helped me identify my } \\
\text { strengths and weaknesses. }\end{array}$ & $\begin{array}{c}\text { Strengths } \\
\text { Inputs from my friends helped } \\
\text { me develop my speech and } \\
\text { performance. } \\
\text { I tried to present my concerns } \\
\text { in regards to what happened } \\
\text { around me. } \\
\text { Developing a speech was easier } \\
\text { when I understood shared } \\
\text { context between me and my } \\
\text { audience. }\end{array}$ \\
$\begin{array}{c}\text { Weaknesses } \\
\text { Some of the feedbacks only } \\
\text { stated "good" or "nice". }\end{array}$ & $\begin{array}{c}\text { Weaknesses } \\
\text { Some of the feedbacks only } \\
\text { stated "good" or "nice". }\end{array}$ \\
\hline
\end{tabular}

There is not much information in the students' reflection regarding the compassion aspect. However, the information taken from the peer-feedback forms shows that the participants are actively contributing to the development of their peers. The peer-feedback mostly starts with a compliment of the presenter's strengths and is written in the form of suggestion when it refers to the presenter's weaknesses. This shows the existence of respect among the participants, just enough to develop one another.

\section{CONCLUSION AND RECOMMENDATION}

As evidenced by this study, reflective pedagogy model applied in this class serves as an interesting vehicle to develop students' competence, conscience and compassion. First, the reflection is easily integrated to the course design in the curriculum. Second, the process provides students with autonomy in the course of their learning. Third, interaction between students and students as well as students and teacher can facilitate the exploration of shared context and common interests. Finally, it breaks the competencecentered evaluation by taken the aspects of conscience and compassion into consideration in the evaluation.

In retrospect, several adjustment and refinements in the model could improve the effectiveness of learning. A more detailed guideline on the reflective writing might result in a more focused learning experience.

\section{References}

[1] J. Dewey, Experience and Education, New York: Collier Books, Macmillan, 1938

[2] C. Rodgers and D.A. Kolb, "Learning Styles and Learning Spaces: Enhancing Experiential Learning in Higher Education," Academy of Management Learning and Education, vol 4, no. 2, 2005, pp. 193 212.

[3] The International Centre for Jesuit Education. Ignatian Pedagogy: A Practical Approach. Rome, 1993.

[4] D. Schön, The Reflective Practitioner: How Professionals Think in Action, New York: Basic Books, 1983.

[5] A.Y. Kolb and D.A. Kolb, "Learning Styles and Learning Spaces: Enhancing Experiential Learning in Higher Education," Academy of Management Learning and Education, vol 4, no. 2, 2005, pp. 193212.

[6] M.W. Daudelin, "Learning from Experience through Reflection," Organizational Dynamics, vol. 24, no. 3, 1996, pp. 36-48. 
[7] S.R. Jones and E.S. Abes, "Enduring Influences of Service-Learning on College Students' Identity Development," Journal of College Student Development, vol. 45, no. 2, 2004, pp. 149-166.

[8] Y. Wang and R. Rodgers, "Impact of Service-Learning and Social Justice Education on College Students' Cognitive Development," NASPA Journal, vol. 42, no. 2, 2006, pp. 316-377.

[9] D. Schön, Educating the Reflective Practitioner, San Francisco: Jossey-Bass, 1987. 